\title{
BMJ Open Is health literacy associated with antibiotic use, knowledge and awareness of antimicrobial resistance among non-medical university students in Egypt? A cross-sectional study
}

To cite: Mostafa $A$ Abdelzaher A, Rashed S, et al. Is health literacy associated with antibiotic use, knowledge and awareness of antimicrobial resistance among non-medical university students in Egypt? A cross-sectional study. BMJ Open 2021;11:e046453. doi:10.1136/ bmjopen-2020-046453

- Prepublication history and supplemental material for this paper is available online. To view these files, please visit the journal online (http://dx.doi. org/10.1136/bmjopen-2020046453).

Received 29 0ctober 2020 Revised 06 February 2021 Accepted 10 February 2021

Check for updates

(C) Author(s) (or their employer(s)) 2021. Re-use permitted under CC BY-NC. No commercial re-use. See rights and permissions. Published by BMJ.

${ }^{1}$ Department of Community, Environmental, and Occupational Medicine, Ain Shams University Faculty of Medicine, Cairo, Egypt ${ }^{2}$ Ain Shams University Faculty of Medicine, Cairo, Egypt

Correspondence to Dr Aya Mostafa; aya.kamaleldin@med.asu. edu.eg

\section{ABSTRACT}

Objectives Antibiotic resistance is a global public health concern, especially in developing countries, where antibiotic misuse is widespread. However, studies investigating relevant factors, particularly in youth, are limited. This study examined the levels of health literacy $(\mathrm{HL})$ and their association with antibiotic use, knowledge of antibiotics and awareness of antibiotic resistance among university students in Egypt.

Design A cross-sectional study was conducted using self-administered questionnaires during 2018. The Health Literacy Survey (HLS-EU-Q16) and the WHO Antibiotic resistance: Multi-Country Public Awareness Survey were used. Bivariate and multivariable analyses were used to compare responses on use and knowledge of antibiotics, and awareness of antibiotic resistance between the three levels of students' HL.

Setting University, Cairo, Egypt.

Participants 508 non-medical university students. Outcomes Students' HL scores were categorised into sufficient, problematic and inadequate. Students' knowledge of antibiotics was categorised into good and poor. Students' awareness of antibiotic resistance was categorised into high, average and poor.

Results $35.1 \%$ of students had sufficient HL. $79.7 \%$ of students had poor knowledge of antibiotics. 39.9\% of students reported having used antibiotics in the past month without a prescription. 92.2\% had limited awareness of antibiotic resistance and $30.6 \%$ of students heard about the term 'antimicrobial resistance'. Background characteristics did not significantly differ by HL levels or knowledge scores, except for students' year of study. Sufficient HL was independently associated with students' high awareness of antibiotic resistance (adjusted $\mathrm{OR}=2.8 ; 95 \% \mathrm{Cl}: 1.3$ to 5.9 ).

Conclusions HL was insufficient in this sample of nonmedical Egyptian university students. Across all levels of $\mathrm{HL}$, knowledge of antibiotics and awareness of antibiotic resistance were limited, reflecting deficiency in relevant education programmes. Findings suggest that sufficient HL supports high awareness of antibiotic resistance. Incorporating HL and rational antibiotic use awareness
Strengths and limitations of this study

- This study is one of the first attempts in low-income and middle-income countries to assess how health literacy levels are associated with antibiotic use, knowledge of antibiotics and awareness of antibiotic resistance among non-medical university students.

- The survey items were adapted from previously tested questionnaires in different populations and in Egypt: The Health Literacy Survey (HLS-EU-Q16) and the WHO Antibiotic Resistance: Multi-Country Public Awareness Survey.

- Using self-administered survey could help avoid socially desirable answers and allowed exploration of several aspects pertinent to students' knowledge of antibiotic use that previous studies recommended addressing, however, in-depth investigation did not seem feasible using the current study design.

- The cross-sectional nature of the study and the convenience sample of 508 non-medical university students means these findings may not be representing the wider views of university students in Egypt, however, this exploratory study may provide preliminary insights to cover the gap in knowledge about the association between university students' health literacy, antibiotic use, knowledge of antibiotics and awareness of antibiotic resistance.

- The possible risk factors explored in this study could guide future investigations and assist policymakers in designing interventions for antimicrobial resistance containment, which address the specific needs of university students in low-income and middle-income countries, where self-medication with antibiotics is widespread.

raising programmes in university curricula is an urgent necessity to curb antibiotic resistance.

\section{INTRODUCTION}

Antimicrobials, including antibiotics, are a shared high-value global asset that is 
exploited in developing and developed countries. The worldwide surge in antimicrobial resistance (AMR) threatens public health and derails sustainable development goals. ${ }^{12}$ AMR attributes to 700000 deaths annually, ${ }^{3}$ and forces 24 million people into extreme poverty. ${ }^{4}$ By 2050, AMR may attribute to 10 million annual deaths, at a global cumulative cost of US $\$ 100$ trillion. ${ }^{3}$ These impacts will unequally affect low/middle-income countries (LMICs). ${ }^{34}$

To concert global efforts in tackling AMR, the WHO developed a Global Action Plan in 2015. ${ }^{1}$ The first objective of this plan was strategically prioritised to enhance knowledge and awareness of AMR through effective communication and education of the public, policymakers, and health and agriculture professionals. ${ }^{1}$ Implementing this objective is particularly important in LMICs, where antibiotics are widely used without prescription. ${ }^{1}$

The 2015 WHO Antibiotic Resistance: Multi-Country Public Awareness Survey reported that levels of awareness of AMR are mixed, reflecting an insufficient understanding of its causes and its management. ${ }^{5}$ Responses from the 12 participating countries varied widely. For instance, awareness of the term 'antibiotic resistance' was $89 \%$ in Mexico and only $22 \%$ in Egypt. ${ }^{5}$ In Egypt, selfmedication is a common practice. ${ }^{6}$ In $2015,53.9 \%$ of Egyptians used antibiotics without prescriptions. ${ }^{7}$ Antibiotic misuse among Egyptian university students was $58.8 \%{ }^{8}$

An in-depth investigation of why younger generations, especially the well-educated, report such high rates of antibiotic misuse is warranted. The association between health literacy (HL) and AMR has been scarcely studied in general, and among youth in particular. To the authors' knowledge, only one such study has been conducted in 2016 among the general population in Germany, a high-income country (HIC).$^{9}$ Antibiotic use was lower in participants with sufficient HL $(28 \%)$ in comparison to participants with problematic $(42 \%)$ and inadequate (41\%) HL. ${ }^{9}$

Comprehensive HL (CHL) is the ability to obtain health-related knowledge, understand and apply it to improve the quality of life.$^{10}$ In this context, antibiotic use and knowledge of AMR are applications of CHL. ${ }^{11}$ Studies in migrants ${ }^{12}$ and in developing countries, including in Egypt, ${ }^{13}$ denoted limited HL was prevalent. Higher education per se without dedicated programmes may not positively impact CHL. ${ }^{14}$ Medical students in the USA, ${ }^{14}$ an HIC and China ${ }^{15}$ reported low rates of HL. Hence, untrained medical and non-medical students might be alike in this sense. ${ }^{16}$

In Egypt, non-medical students form a majority of university students (3.1 million). ${ }^{17}$ They can lead community change through raising awareness and correcting misperceptions. Understanding whether university students' HL affects their awareness of AMR will help identify possible risk factors and tailor interventions to address their specific needs. Furthermore, the scarcity of such studies in HICs and LMICs drives the need to cover this gap of knowledge. To inform future policies in this regard, such as Egypt's National Action Plan for Antimicrobial Resistance, ${ }^{18}$ this study examined levels of HL and their association with antibiotic use, knowledge of antibiotics and awareness of antibiotic resistance among university students in Egypt.

\section{METHODS}

\section{Study design and setting}

A cross-sectional study was conducted among nonmedical students at Ain Shams University (ASU) between February and June 2018 using self-administered questionnaires. ASU is a public university with approximately 200000 students and encompasses 16 faculties and three institutes with seven campuses that are all located in Cairo, Egypt. ${ }^{19}$

\section{Study sample and data collection}

A convenience sample of non-medical students who attended ASU faculties and institutes, except those related to the medical field (Medicine, Pharmacy, Nursing and Dentistry), was sought. A sample size of 456 was calculated at a $\mathrm{CI}=99 \%$, a margin of error $=5 \%$, based on the previously reported level of public awareness of the term 'antibiotic resistance' (22\%) in Egypt. ${ }^{5}$ After pre-testing the questionnaire, a pilot study was done on 50 non-medical students; results were discussed by the research team to: exchange field experiences, ensure data collection was carried out in a consistent manner, confirm clarity of the questions and the answer categories, and agree on standard explanatory phrases for each question. Pilot data were not included in this analysis; based on the pilot results, the authors added approximately $10 \%(\mathrm{n}=52)$ to accommodate for possible missing data; the target sample size was 508 non-medical students. Questionnaires were distributed by 50 trained medical students at ASU; each of whom approached approximately 10 individuals, one at a time and asked a screening question to identify nonmedical students at different ASU campuses. If the individual was a non-medical student, those distributing the questionnaire read aloud a written information sheet (to standardise the information conveyed) introducing the research team, the study aims, its public health benefit and the time needed for completing the questionnaire. Also, it was conveyed that participation was voluntary, withdrawal was free at any time, confidentiality and anonymity were ensured and that data will be published collectively. Research team's contacts were provided for any inquiries. Non-medical students who were interested to participate provided verbal consent, which was recorded by ticking a box in the questionnaire paper form, before completing the questionnaire. Participants were not provided any incentives for completing the study. Approximately $2 \%$ of the approached students refused to participate; reasons for non-response were mainly having no time or no interest in the study. Data were collected until the target sample size was achieved. After completing the survey, 
participants were given printed health education material about AMR.

\section{Study tools}

The 35-item questionnaire was adapted from previous literature and included three sections: demographic characteristics (six items: age, gender, residence, marital status, faculty and academic year); HL (16 items: using the European Health Literacy Survey Questionnaire-modified short version: HLS-EU-Q16) ${ }^{20}$; and use of antibiotic, knowledge of antibiotics and awareness of antibiotic resistance (13 items: adapted from the WHO Antibiotic Resistance: Multi-Country Public Awareness Survey). ${ }^{5}$

\section{The European Health Literacy Survey Questionnaire—modified} short version (HLS-EU-Q16)

The modified HLS-EU-Q16 ${ }^{20}$ included 16 closed-ended questions covering three health domains: healthcare (questions 1-7), disease prevention (questions 8-12) and health promotion (questions 13-16), and assessing four dimensions of CHL: participants' perceived ability to access, comprehend, appraise and apply health information (see online supplemental file 1). The HLS-EU-Q16 was originally developed as part of the European Health Literacy project ${ }^{21}$; an Arabic version was available and tested previously among Arabic speaking migrants. ${ }^{12} 20$ The authors used the modified HLS-EU-Q16 because it allowed simple and fast assessment of HL and its Arabic version was used in a previous study in Egypt. ${ }^{13}$ Its internal consistency reliability using Crohnbach's alpha in the current study was 0.8 . Following the original method of analysing responses to the HLS-EU-Q16, ${ }^{22}$ the four valid response categories were dichotomised: 'very easy' and 'fairly easy' responses were assigned a value of ' 1 ', where 'fairly difficult' and 'very difficult' were assigned a value of ' 0 '. 'Don't know' responses were treated as missing. ${ }^{20}$ For each participant, a total score was calculated if they had valid responses for $\geq 14$ out of the 16 questions, per Wångdahl et al score calculation instructions. ${ }^{20}$ Participants were then categorised into three levels of HL: participants' scores $\geq 13$ were considered 'sufficient', 9-12 'problematic' and $\leq 8$ 'inadequate' HL. ${ }^{20}$

\section{The WHO Antibiotic Resistance: Multi-Country Public Awareness Survey}

The questions adapted from the WHO's main survey ${ }^{5}$ included 13 closed-ended questions (see online supplemental file 1) covering three aspects: self-reported use of antibiotics (three questions: 1-3), knowledge of antibiotics (four questions: 4-7) and awareness of antibiotic resistance (six questions: 8-13). All questions 1-13 were used in the current study. It was conducted previously in 12 countries, including in Egypt. ${ }^{5}$ The available online version was in English, therefore, it was translated into Arabic; the Arabic version was back translated into English. Face and content validity were assessed by two public health experts. Correct answers were identified from the WHO report. ${ }^{5}$ Accordingly, each correct answer was assigned a score of ' 1 ' and otherwise (ie, not correct or 'don't know' answers) a score of ' 0 '. Also, 5-point Likert scale responses were dichotomised: if the correct answers were 'agree' or 'strongly agree', these were combined and assigned a score of ' 1 ' and otherwise a score of ' 0 ' and vice versa. A total score for 'level of knowledge of antibiotics' was calculated for each participant using questions 4-7 (15 items, as question 7 has 12 subitems). The total score for 'level of knowledge of antibiotics' ranged from 0 to 15; percentage scores were calculated for each participant. For subsequent analysis, percentage scores $<50 \%$ were considered 'poor' and $\geq 50 \%$ were considered 'good' level of knowledge of antibiotics. Similarly, a total score for 'level of awareness of antibiotic resistance' was calculated for each participant using questions: 10-12 (22 items, as each of questions 10 and 11 has eight subitems, and question 12 has six subitems). The total score for 'level of awareness of antibiotic resistance' ranged from 0 to 22; percentage scores were calculated for each participant. For subsequent analysis, percentage scores $<50 \%$ were considered 'poor', $50 \%$ to $<75 \%$ were considered 'average' and $\geq 75 \%$ were considered 'high' level of awareness of antibiotic resistance. Additionally, if the participant was aware of any of the terms related to antibiotic resistance under question 8 , the participant was considered 'aware of antibiotic resistance'.

\section{Statistical analysis}

Anonymously filled questionnaires were assigned serial identification numbers. Data were analysed using SPSS (Statistical Package for the Social Sciences, V.25, SPSS). Descriptive statistics were performed and presented as frequency and percentages for qualitative variables or mean and SD for quantitative variables. Bivariate analyses were performed using the $\chi^{2}$ test or the independent samples t-test or the analysis of variance test. For the regression analysis, the following variables were dichotomised: HL into 'sufficient' and 'insufficient' (combining 'inadequate' and 'problematic'), and level of awareness of antibiotic resistance into 'high' and 'not high' (combining 'poor' and 'average'). Bivariable and multivariable binary logistic regression analyses were performed to identify factors significantly associated with sufficient HL, good level of knowledge of antibiotics, awareness of antibiotic resistance and high level of awareness of antibiotic resistance. Adjusted odds ratios (adjusted ORs) and 95\% CIs are reported. A p value $\leq 0.05$ was considered statistically significant.

\section{Patient and public involvement}

Patient and public were not involved in the development of the research question and outcome measures, the design, recruitment and conduct of the study. The results of this study will be disseminated to study participants via newsletters and social media outlets.

\section{RESULTS}

\section{Sample characteristics}

Students' mean age was $20.5 \pm 1.3$ years old, ranging from 18 to 26 years. Most of students were women (66.3\%), 
Table 1 Background characteristics and level of health literacy among non-medical students

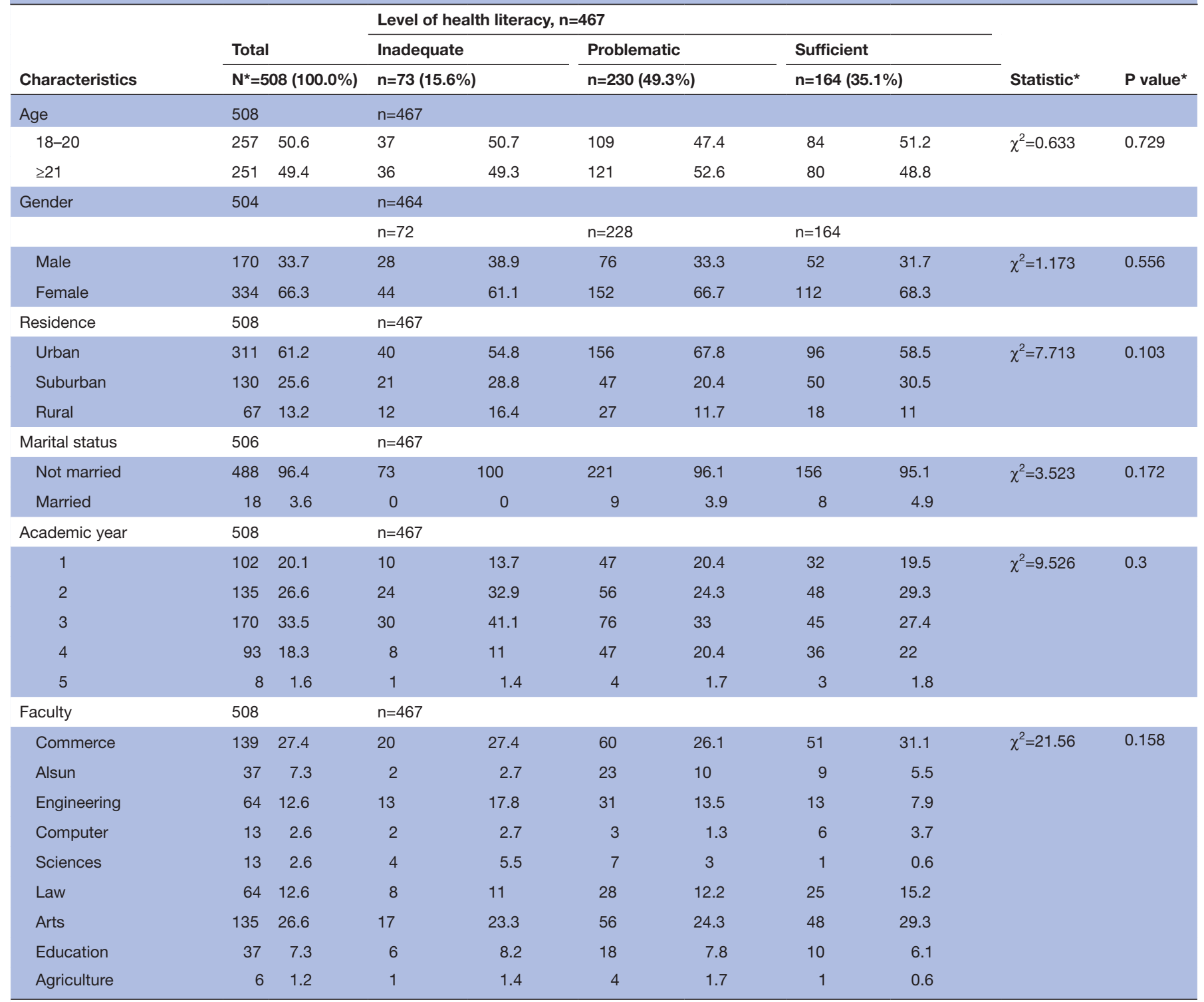

*Some values are missing, missing data not included.

${ }^{*} \chi^{2}$ test.

urban residents $(61.2 \%)$ and unmarried $(96.4 \%)$. Eighty per cent of students were in years $1-3$ of their studies. The most represented faculties were commerce $(27.4 \%)$ and arts $(26.6 \%)$ (table 1$)$.

\section{Health literacy}

Approximately one-third $(35.1 \%)$ of participants had sufficient HL, while $49.3 \%$ and $15.6 \%$ had problematic and inadequate HL, respectively. There were no statistically significant differences in HL levels by different demographic characteristics (table 1). Details of assessment of HL are presented in online supplemental table 1. Most students $(92.0 \%)$ found it easy to understand the doctor's or pharmacists' instructions on how to take a prescribed medicine, whereas more than half $(52.3 \%)$ of participants found it difficult to find information about managing mental health problems.

\section{Use of antibiotics}

Approximately two-fifths (38.0\%) of students reported having used antibiotics 1 month ago, while $62.3 \%$ used antibiotics in the last 12 months. Forty per cent did not get their antibiotics based on a prescription and 33.7\% did not get professional medical advice on how to take them (table 2). There were no statistically significant differences in students' use of antibiotic between the three HL levels (table 2).

\section{Knowledge of antibiotics}

Thirty-eight per cent of students thought they should stop taking antibiotics once they felt better. Thirty-nine per cent believed it is okay to take the same antibiotics that were given to a friend or a family member to treat the same illness. More than half of students $(51.8 \%)$ stated 
Table 2 Antibiotic use and level of health literacy among non-medical students

\begin{tabular}{|c|c|c|c|c|c|c|c|c|c|c|}
\hline \multirow[b]{3}{*}{ Antibiotic use } & \multirow{2}{*}{\multicolumn{2}{|c|}{ Total }} & \multicolumn{6}{|c|}{ Level of health literacy, $n=467$} & \multirow[b]{3}{*}{$\chi^{2}$} & \multirow{3}{*}{$\begin{array}{l}\mathbf{P} \\
\text { valuet }\end{array}$} \\
\hline & & & \multirow{2}{*}{$\begin{array}{l}\text { Inadequate } \\
\mathrm{n}^{*}\end{array}$} & \multicolumn{3}{|c|}{ Problematic } & \multicolumn{2}{|c|}{ Sufficient } & & \\
\hline & $\mathbf{N}^{*}$ & $\%$ & & $\%$ & $n^{*}$ & $\%$ & $\mathrm{n}^{*}$ & $\%$ & & \\
\hline & $\mathrm{n}=498$ & & $\mathrm{n}=73$ & & $\mathrm{n}=227$ & & $n=163$ & & & \\
\hline One month ago & 189 & 38 & 34 & 46.6 & 86 & 37.9 & 55 & 33.7 & 13.134 & 0.216 \\
\hline More than a year ago & 29 & 5.8 & 2 & 2.7 & 14 & 8.4 & 10 & 6.1 & & \\
\hline Never & 17 & 3.4 & 3 & 4.1 & 5 & 2.2 & 7 & 4.3 & & \\
\hline Can't remember & 142 & 28.5 & 20 & 27.4 & 57 & 25.1 & 52 & 31.9 & & \\
\hline
\end{tabular}

On that occasion, did you get the antibiotics by a prescription $n=341$

from a doctor or nurse? $n=366$

\begin{tabular}{|c|c|c|c|c|c|c|c|c|c|c|}
\hline & \multicolumn{2}{|c|}{$n=366$} & \multicolumn{2}{|l|}{$n=52$} & \multicolumn{2}{|c|}{$\mathrm{n}=174$} & \multicolumn{4}{|c|}{$n=115$} \\
\hline Yes & 207 & 56.6 & 32 & 61.5 & 95 & 54.6 & 67 & 58.3 & 2.751 & 0.6 \\
\hline No & 146 & 39.9 & 18 & 34.6 & 75 & 43.1 & 47 & 40.9 & & \\
\hline \multicolumn{3}{|c|}{$\begin{array}{l}\text { On that occasion, did you get advice from a doctor, nurse or } \\
\text { pharmacist on how to take them? } n=353\end{array}$} & $\mathrm{n}=332$ & & & & & & & \\
\hline No & 119 & 33.7 & 19 & 38 & 51 & 30.5 & 37 & 32.2 & & \\
\hline Can't remember & 0 & 0 & - & & - & & - & & & \\
\hline
\end{tabular}

*Some values are missing, missing data not included.

$+\chi^{2}$ test.

it was 'okay' to buy the same antibiotic or request it from a doctor if sick and they helped them get better when they had the same symptoms before (table 3). From a list of medical conditions that were caused by bacteria or viruses, approximately three-quarters of students incorrectly thought antibiotics treat sore throat or cold and influenza. Almost half of students incorrectly thought antibiotics treat fever and diarrhoea. Most students did not know if antibiotics treat gonorrhoea, malaria, measles and HIV (table 3).

Only a fifth $(20.3 \%)$ of students had a good level of knowledge of antibiotics (table 4). There was no statistically significant difference in good knowledge of antibiotics between the three HL levels or by demographic characteristics, except by students' year of study. Students in their third to fifth years of study showed a relatively higher proportion of good knowledge of antibiotics compared with younger students in their first or second years of study (table 4).

\section{Awareness of antibiotic resistance}

Approximately two-fifths (39.5\%) of students did not know the term 'antibiotic resistance', and less than one-third (30.6\%) heard about the term 'antimicrobial resistance'. More than half $(57.4 \%)$ of students incorrectly thought antibiotic resistance occurs when their body becomes resistant to antibiotics, $43.3 \%$ incorrectly thought antibiotic resistance is only a problem for people who take antibiotics regularly and $53.8 \%$ did not know if antibiotics were used in agriculture (table 5 ).

Most students $(55.0 \%)$ with sufficient HL agreed that pharmaceutical companies should develop new antibiotics, a proportion significantly higher than students with problematic $(48.2 \%)$ and inadequate HL $(41.1 \%)$ (online supplemental table 2). Only $7.8 \%$ of students had a high level of awareness of antibiotic resistance. Among those, only $13.2 \%$ had sufficient HL (table 6). Older students and those in advanced study years significantly showed a higher level of awareness of antibiotic resistance compared with their counterparts (table 6).

The association between levels of $\mathrm{HL}$, level of knowledge of antibiotics and level of awareness of antibiotic resistance

In the multivariable logistic regression, students' good level of knowledge of antibiotic resistance was significantly higher in advanced students' years of study, specifically the third (adjusted OR=4.5; 95\% CI: 1.7 to 11.8 ) and the fourth years (adjusted OR=4.4; 95\% CI: 1.4 to 13.5), but was not associated with sufficient HL. Students' high level of awareness of antibiotic resistance was independently associated with students' sufficient HL (adjusted $\mathrm{OR}=2.8$; 95\% CI: 1.3 to 5.9) and good level of antibiotic knowledge (adjusted OR=4.2; 95\% CI: 1.9 to 8.8) (table 7). 
Table 3 Knowledge of antibiotics and health literacy among non-medical students

\begin{tabular}{|c|c|c|c|c|c|c|c|c|c|c|}
\hline \multirow[b]{3}{*}{ Knowledge of antibiotics } & \multicolumn{8}{|c|}{ Level of health literacy, $n=467$} & \multirow[b]{3}{*}{$\chi^{2}$} & \multirow[b]{3}{*}{$P$ value } \\
\hline & \multicolumn{2}{|l|}{ Total } & \multicolumn{2}{|c|}{ Inadequate } & \multicolumn{2}{|c|}{ Problematic } & \multicolumn{2}{|c|}{ Sufficient } & & \\
\hline & $\mathbf{N}^{*}$ & $\%$ & $n^{*}$ & $\%$ & $\mathrm{n}^{*}$ & $\%$ & $\mathrm{n}^{*}$ & $\%$ & & \\
\hline & $\mathrm{n}=497$ & & $\mathrm{n}=73$ & & $\mathrm{n}=228$ & & $n=160$ & & & \\
\hline When you feel better & 188 & 37.8 & 22 & 30.1 & 80 & 35.1 & 70 & 43.8 & 10.663 & 0.031 \\
\hline Don't know & 42 & 8.5 & 11 & 15.1 & 19 & 8.3 & 7 & 4.4 & & \\
\hline \multicolumn{3}{|c|}{$\begin{array}{l}\text { Do you think this statement is 'true' or 'false'? 'It's okay to use } \\
\text { antibiotics that were given to a friend or family member, as long as } \\
\text { they were used to treat the same illness' } n=499\end{array}$} & \multicolumn{2}{|c|}{$\mathrm{n}=465$} & & & & & & \\
\hline & $\mathrm{n}=499$ & & $\mathrm{n}=73$ & & $\mathrm{n}=229$ & & $n=163$ & & & \\
\hline \multicolumn{3}{|c|}{$\begin{array}{l}\text { Do you think this statement is 'true' or 'false'? 'It's okay to buy the } \\
\text { same antibiotics, or request them from a doctor, if you're sick and } \\
\text { they helped you get better when you had the same symptoms before' } \\
n=500\end{array}$} & \multicolumn{2}{|c|}{$\mathrm{n}=464$} & & & & & & \\
\hline & \multicolumn{2}{|c|}{$n=500$} & \multicolumn{2}{|c|}{$\mathrm{n}=73$} & \multicolumn{2}{|c|}{$n=228$} & \multicolumn{2}{|l|}{$\mathrm{n}=163$} & & \\
\hline True & 259 & 51.8 & 41 & 56.2 & 112 & 49.1 & 87 & 53.4 & 1.757 & 0.78 \\
\hline False & 188 & 37.6 & 26 & 35.6 & 92 & 40.4 & 58 & 35.6 & & \\
\hline Don't know & 53 & 10.6 & 6 & 8.2 & 24 & 10.5 & 18 & 11 & & \\
\hline
\end{tabular}

Do you think these conditions can be treated with antibiotics?

\begin{tabular}{|c|c|c|c|c|c|c|c|c|c|c|}
\hline HIV/AIDS & 500 & & $n=464$ & & & & & & & \\
\hline & & & $\mathrm{n}=73$ & & $\mathrm{n}=228$ & & $n=163$ & & & \\
\hline No & 191 & 38.2 & 27 & 37 & 88 & 38.6 & 64 & 39.3 & 4.907 & 0.297 \\
\hline Don’t know & 255 & 51 & 39 & 53.4 & 108 & 47.4 & 87 & 53.4 & & \\
\hline Gonorrhoea & 500 & & $n=463$ & & & & & & & \\
\hline Yes & 67 & 13.4 & 9 & 12.5 & 39 & 17.1 & 17 & 10.4 & & \\
\hline Don’t know & 347 & 69.4 & 58 & 80.6 & 155 & 68 & 107 & 65.6 & & \\
\hline \multirow[t]{2}{*}{ Bladder or urinary tract infection } & 500 & & $n=463$ & & & & & & & \\
\hline & & & $\mathrm{n}=72$ & & $\mathrm{n}=228$ & & $n=163$ & & & \\
\hline \multirow[t]{2}{*}{ Diarrhoea } & 500 & & $n=463$ & & & & & & & \\
\hline & & & $n=73$ & & $\mathrm{n}=228$ & & $\mathrm{n}=162$ & & & \\
\hline No & 151 & 30.2 & 13 & 17.8 & 82 & 36 & 49 & 30.2 & 9.513 & 0.049 \\
\hline Yes & 207 & 41.4 & 33 & 45.2 & 88 & 38.6 & 70 & 43.2 & & \\
\hline Don't know & 142 & 28.4 & 27 & 37 & 58 & 25.4 & 43 & 26.5 & & \\
\hline \multirow[t]{2}{*}{ Cold and influenza } & 500 & & $n=463$ & & & & & & & \\
\hline & & & $n=73$ & & $\mathrm{n}=228$ & & $\mathrm{n}=162$ & & & \\
\hline No & 90 & 18 & 10 & 13.7 & 38 & 16.7 & 37 & 22.8 & 12.897 & 0.012 \\
\hline Yes & 364 & 72.8 & 50 & 68.5 & 176 & 77.2 & 112 & 69.1 & & \\
\hline Don't know & 46 & 9.2 & 13 & 17.8 & 14 & 6.1 & 13 & 8 & & \\
\hline
\end{tabular}


Table 3 Continued

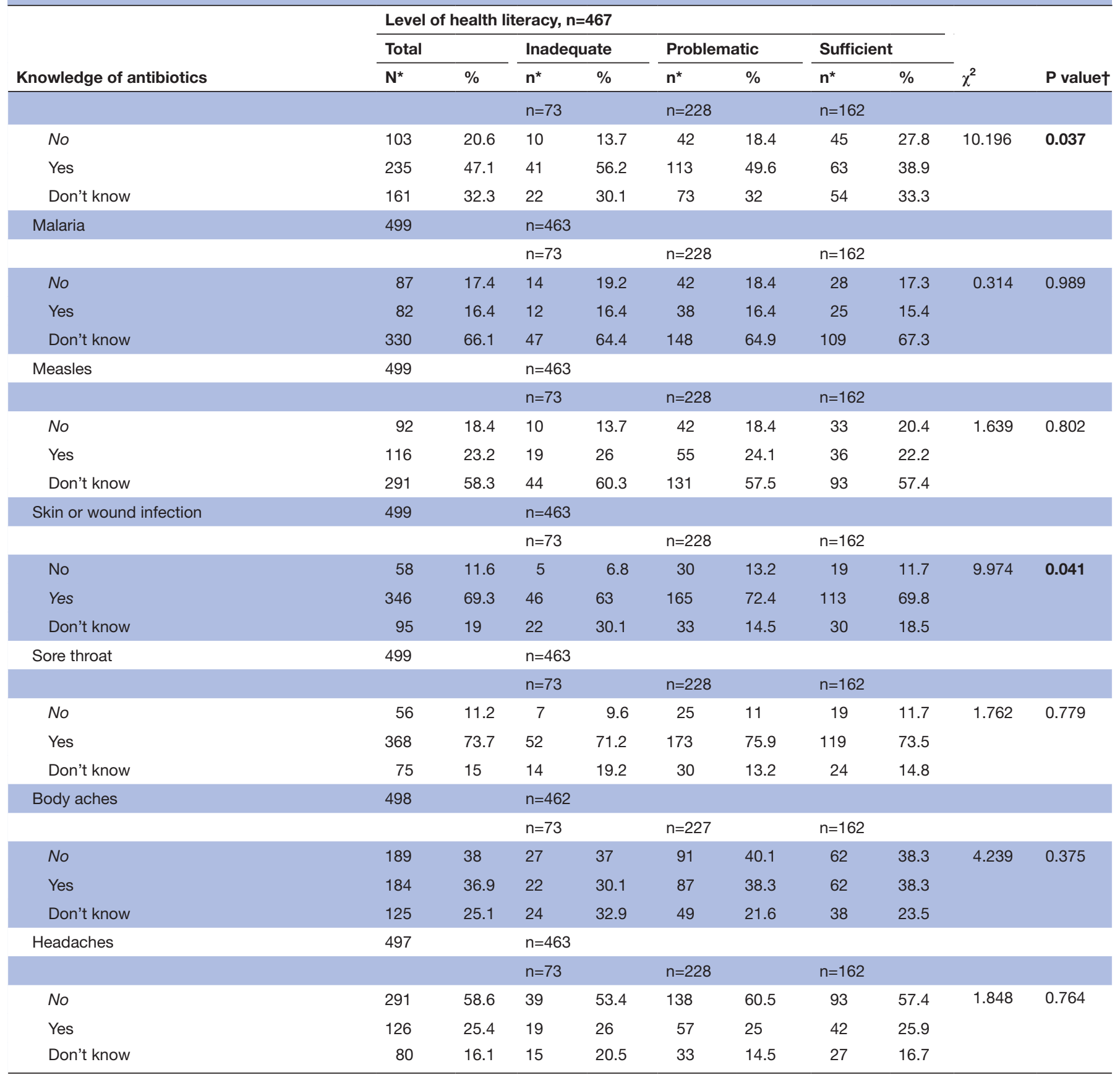

Correct answers are italicised.

Statistically significant $\mathrm{P}$-values $\leq 0.05$ are in bold.

*Some values are missing, missing data not included.

$+\chi^{2}$ test.

\section{DISCUSSION}

This study is one the first attempts to assess CHL levels among non-medical university students and compare these with students' use of antibiotics, knowledge of antibiotics and awareness of AMR in LMICs. Only one-third of students had sufficient HL. Approximately two-fifths of students reported having used antibiotics in the past month without a prescription. Only a fifth of students had a good level of knowledge of antibiotics. Less than one-third of students heard about the term 'antimicrobial resistance' and less than a tenth had a high level of awareness of antibiotic resistance. Sufficient HL was an independent determinant of students' high level of awareness of antibiotic resistance.

Nearly half of the participating students $(49.3 \%)$ had problematic HL, a proportion similar to that reported in a study among outpatient clinics attendees at ASU Hospitals $(46.7 \%){ }^{13}$ However, levels of sufficient HL among students in this study $(35.1 \%)$ were higher than levels reported in outpatient clinic attendees $(18.9 \%) .{ }^{13}$ These 
Table 4 Mean total percentage scores and levels of knowledge of antibiotics among non-medical students by background characteristics and levels of health literacy

\begin{tabular}{|c|c|c|c|c|}
\hline \multirow[b]{4}{*}{ Characteristic } & \multirow[b]{4}{*}{$\mathbf{N}^{*}$} & \multirow[t]{3}{*}{$\begin{array}{l}\text { Mean total } \\
\text { percentage } \\
\text { score of } \\
\text { knowledge } \\
\text { of } \\
\text { antibiotics }\end{array}$} & \multicolumn{2}{|c|}{$\begin{array}{l}\text { Level of knowledge of } \\
\text { antibiotics, } n=488\end{array}$} \\
\hline & & & Poor & Good \\
\hline & & & $n=389$ & $n=99$ \\
\hline & & Mean (SD) & $n^{*}(\%)$ & $n^{*}(\%)$ \\
\hline Total & 488 & 34.1 (17.9) & $289(79.7)$ & 99 (20.3) \\
\hline Age (years) & & & $n=389$ & $n=99$ \\
\hline $18-20$ & 244 & $32.2(17.4)$ & $203(83.2)$ & $41(16.8)$ \\
\hline$\geq 21$ & 244 & 36.0 (18.2) & $186(76.2)$ & $58(23.8)$ \\
\hline Statistic $†$ & & $F=1.404$ & $\chi^{2}=3.662$ & \\
\hline$P$ value & & 0.018 & 0.056 & \\
\hline Gender & $n=485$ & & $n=386$ & $n=99$ \\
\hline Males & 161 & 31.1 (17.5) & $136(84.5)$ & 25 (15.5) \\
\hline Females & 324 & $35.6(17.9)$ & $250(77.2)$ & $74(22.8)$ \\
\hline Statistic† & & $\mathrm{F}=0.438$ & $\chi^{2}=3.539$ & \\
\hline$P$ value & & 0.008 & 0.06 & \\
\hline Residence & $n=488$ & & $n=389$ & $\mathrm{n}=99$ \\
\hline Urban & 63 & 31.9 (19.3) & $51(81.0)$ & $12(19.0)$ \\
\hline Suburban & 123 & 35.0 (19.5) & $96(78.0)$ & 27 (22.0) \\
\hline Rural & 302 & $34.2(16.9)$ & $242(80.1)$ & 60 (19.9) \\
\hline Statistic† & & $F=0.666$ & $\chi^{2}=0.303$ & \\
\hline$P$ value & & 0.514 & 0.859 & \\
\hline Marital status & $n=487$ & & $n=388$ & $\mathrm{n}=99$ \\
\hline Not married & 469 & $33.8(17.7)$ & 376 (80.2) & $93(19.8)$ \\
\hline Married & 18 & $42.9(20.4)$ & $12(66.7)$ & $6(33.3)$ \\
\hline Statistic $†$ & & $F=0.100$ & $\chi^{2}=1.952$ & \\
\hline$P$ value & & 0.033 & 0.226 & \\
\hline Academic year & $n=488$ & & $n=389$ & $\mathrm{n}=99$ \\
\hline 1 & 94 & 30.9 (15.5) & $84(89.4)$ & $10(10.6)$ \\
\hline 2 & 129 & $32.9(17.8)$ & 107 (82.9) & $22(17.1)$ \\
\hline 3 & 166 & $34.9(18.8)$ & $125(75.3)$ & $41(24.7)$ \\
\hline 4 & 91 & 37.1 (18.6) & 67 (73.6) & $24(26.4)$ \\
\hline 5 & 8 & $40.8(11.5)$ & $6(75.0)$ & $2(25.0)$ \\
\hline Statistic $†$ & & $F=1.836$ & $\chi^{2}=10.438$ & \\
\hline$P$ value & & 0.121 & 0.022 & \\
\hline Health literacy & $n=455$ & & $n=361$ & $\mathrm{n}=94$ \\
\hline Inadequate & 71 & $31.2(17.5)$ & $62(87.3)$ & $9(12.7)$ \\
\hline Problematic & 225 & $35.6(17.5)$ & $176(78.2)$ & 49 (21.8) \\
\hline Sufficient & 159 & 34.7 (18.5) & $123(77.4)$ & 36 (22.6) \\
\hline Statistic $†$ & & $F=1.652$ & $\chi^{2}=3.313$ & \\
\hline$P$ value & & 0.193 & 0.191 & \\
\hline
\end{tabular}

*Some values are missing, missing data not included.

$+\chi^{2}$ test or independent samples t-test or one-way analysis of variance.

results were close to those reported in a population-based study in Italy, ${ }^{23}$ where $33 \%$ had sufficient HL and 55.2\% had problematic HL. However, sufficient HL in students in this study were lower than those reported among university students in Lithuania, ${ }^{24}$ where the majority of students $(70 \%)$ attended health education courses and two-thirds of the students $(67 \%)$ had sufficient HL. This might indicate the vital role of dedicated courses in raising HL levels.

The total use of antibiotics among students in this study $(38.0 \%)$ was equal to the total country average use reported in the WHO multi-country survey by respondents with higher education (representing $68 \%$ of the study sample). ${ }^{5}$ Respondents in the WHO survey with no education reported taking 1.1 times antibiotics in the past month compared with respondents with higher education. ${ }^{5}$ However, students with inadequate HL reported taking 1.4 times antibiotics in the past month as compared with students with sufficient HL in this study. This finding reflects the important role of $\mathrm{HL}$ in rational use of antibiotics, however, there are determinants of illness and health that might influence such association.

Self-medication of antibiotics involves obtaining them without a prescription to treat self- diagnosed symptoms or conditions. ${ }^{25-28}$ Self-medication of antibiotics was common $(39.9 \%)$ in all students regardless of their level of HL. A similar rate $(39.5 \%)$ was reported recently among university students in the $\operatorname{UAE}(38.2 \%),{ }^{29} \mathrm{Sri}$ Lanka $(38.6 \%),{ }^{30}$ China $(33.0 \%)^{31}$ and in an earlier household study in Jordan (39.5\%). ${ }^{32}$ The rate of selfmedication of antibiotics among students in this study was 1.5 times higher than that reported for Egypt in the WHO survey $(26 \%){ }^{5}$ This observation entails a further wider investigation in different HICs and LMICs on why individuals with higher educational levels practice selfmedication of antibiotics.

The misuse of antibiotics for self-limiting illnesses, such as cold and influenza, sore throat, and diarrhoea, is the most important contributing factor for rising AMR. ${ }^{33}$ Overall, only one in five students in this study had good knowledge of antibiotics, which is lower than rates among non-medical students (one in three) in Nigeria, ${ }^{34}$ another LMIC. However, in line with the current study results, the year of study was associated with knowledge of antibiotics use, while most students' demographic characteristics were not significantly associated with knowledge scores of the Nigerian students. ${ }^{34}$ Although students with sufficient HL in the current study reported significantly higher rates of correct answers than students with lower HL levels for conditions treatable with antibiotics, particularly cold, influenza and fever, this was not true for other conditions, such as gonorrhoea. This indicates that students have mixed perceptions and incomplete knowledge of antibiotics, even among students with sufficient HL.

Approximately, 4 in 10 students knew the term 'antibiotic resistance', which is about half the average reported for all participating countries (7 in 10) in the WHO survey. ${ }^{5}$ Despite this, the rate detected among students in this study was twice as high as that reported for Egyptians in the WHO survey (one in five).$^{5}$ Respondents in the WHO survey with a higher educational level were more 
Table 5 Awareness of antibiotic resistance and level of health literacy among non-medical students

\begin{tabular}{|c|c|c|c|c|c|c|c|c|c|c|}
\hline \multirow[b]{3}{*}{ Awareness of antibiotic resistance } & \multicolumn{8}{|c|}{ Level of health literacy, $n=467$} & \multirow[b]{3}{*}{$\chi^{2}$} & \multirow[b]{3}{*}{ P value } \\
\hline & \multicolumn{2}{|c|}{ Total } & \multicolumn{2}{|c|}{ Inadequate } & \multicolumn{2}{|c|}{ Problematic } & \multicolumn{2}{|c|}{ Sufficient } & & \\
\hline & $\mathbf{N}^{*}$ & $\%$ & $\mathbf{n}^{*}$ & $\%$ & $\mathrm{n}^{*}$ & $\%$ & $\mathrm{n}^{*}$ & $\%$ & & \\
\hline \multicolumn{11}{|c|}{ Have you heard of any of the following terms } \\
\hline \multirow[t]{2}{*}{ Antibiotic resistance } & \multicolumn{2}{|l|}{496} & \multicolumn{4}{|c|}{$n=462$} & & & & \\
\hline & & & \multicolumn{2}{|c|}{$\mathrm{n}=72$} & \multicolumn{2}{|c|}{$n=228$} & \multicolumn{2}{|c|}{$n=162$} & & \\
\hline No & 196 & 39.5 & 28 & 38.9 & 94 & 41.2 & 63 & 38.9 & 2.904 & 0.574 \\
\hline Yes & 215 & 43.3 & 29 & 40.3 & 104 & 45.6 & 71 & 43.8 & & \\
\hline Don't know & 85 & 17.1 & 15 & 20.8 & 30 & 13.2 & 28 & 17.3 & & \\
\hline \multirow[t]{2}{*}{ Superbugs } & \multicolumn{2}{|l|}{496} & \multicolumn{4}{|c|}{$\mathrm{n}=461$} & & & & \\
\hline & & & \multicolumn{2}{|c|}{$\mathrm{n}=72$} & \multicolumn{2}{|c|}{$\mathrm{n}=228$} & \multicolumn{2}{|c|}{$n=161$} & & \\
\hline No & 281 & 56.7 & 44 & 61.1 & 136 & 59.6 & 83 & 51.6 & 7.965 & 0.093 \\
\hline Yes & 106 & 21.4 & 10 & 13.9 & 54 & 23.7 & 37 & 23 & & \\
\hline Don't know & 109 & 22 & 18 & 25 & 38 & 16.7 & 41 & 25.5 & & \\
\hline \multirow[t]{2}{*}{ Antimicrobial resistance } & \multicolumn{2}{|l|}{496} & \multicolumn{4}{|c|}{$n=461$} & & & & \\
\hline & & & $\mathrm{n}=7$ & & $\mathrm{n}=228$ & & $n=160$ & & & \\
\hline No & 235 & 47.4 & 41 & 56.2 & 112 & 49.1 & 69 & 43.1 & 6.857 & 0.144 \\
\hline Yes & 152 & 30.6 & 15 & 20.5 & 75 & 32.9 & 52 & 32.5 & & \\
\hline Don't know & 109 & 22 & 17 & 23.3 & 41 & 18 & 39 & 24.4 & & \\
\hline Drug resistance & 497 & & $\mathrm{n}=4$ & & & & & & & \\
\hline & & & $\mathrm{n}=7$ & & $\mathrm{n}=228$ & & $\mathrm{n}=161$ & & & \\
\hline No & 201 & 40.4 & 36 & 49.3 & 96 & 42.1 & 56 & 34.8 & 11.689 & 0.02 \\
\hline Yes & 185 & 37.2 & 22 & 30.1 & 95 & 41.7 & 59 & 36.6 & & \\
\hline Don't know & 111 & 22.3 & 15 & 20.5 & 37 & 16.2 & 46 & 28.6 & & \\
\hline Antibiotic-resistant bacteria & 490 & & $\mathrm{n}=4$ & & & & & & & \\
\hline & & & $\mathrm{n}=7$ & & $\mathrm{n}=224$ & & $n=158$ & & & \\
\hline No & 165 & 33.7 & 30 & 41.1 & 75 & 33.5 & 51 & 32.3 & 6.488 & 0.166 \\
\hline Yes & 219 & 44.7 & 26 & 35.6 & 112 & 50 & 70 & 44.3 & & \\
\hline Don't know & 106 & 21.6 & 17 & 23.3 & 37 & 16.5 & 37 & 23.4 & & \\
\hline Please indicate whether you think the $f$ & ents a & le' or ' & & & & & & & & \\
\hline $\begin{array}{l}\text { 'Antibiotic resistance occurs when you } \\
\text { antibiotics and they no longer work as }\end{array}$ & s resis & & $\mathrm{n}=4$ & & & & & & & \\
\hline & $n=49$ & & $\mathrm{n}=7$ & & $\mathrm{n}=224$ & & $n=160$ & & & \\
\hline False & 55 & 11.2 & 8 & 11 & 27 & 12.1 & 15 & 9.4 & 3.966 & 0.411 \\
\hline True & 282 & 57.4 & 42 & 57.5 & 120 & 53.6 & 102 & 63.7 & & \\
\hline Don't know & 154 & 31.4 & 23 & 31.5 & 77 & 34.4 & 43 & 26.9 & & \\
\hline $\begin{array}{l}\text { 'Many infections are becoming increas } \\
\text { antibiotics' } n=490\end{array}$ & treat & & $\mathrm{n}=4$ & & & & & & & \\
\hline & $n=49$ & & $\mathrm{n}=7$ & & $\mathrm{n}=223$ & & $n=159$ & & & \\
\hline False & 65 & 13.3 & 10 & 13.7 & 24 & 10.8 & 24 & 15.1 & 2.082 & 0.721 \\
\hline True & 249 & 50.8 & 35 & 47.9 & 120 & 53.8 & 80 & 50.3 & & \\
\hline Don't know & 176 & 35.9 & 28 & 38.4 & 79 & 35.4 & 55 & 34.6 & & \\
\hline
\end{tabular}

'If bacteria are resistant to antibiotics, it can be very difficult or impossible to $n=457$

treat the infections they cause' $n=492$

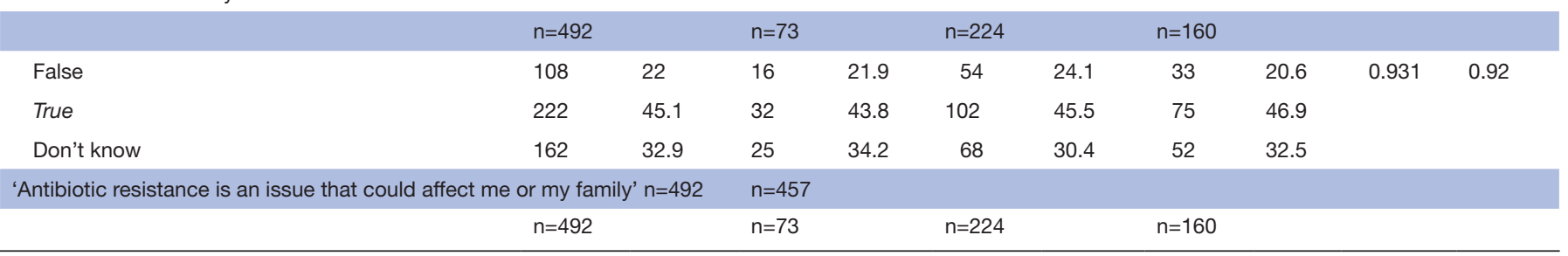


Table 5 Continued

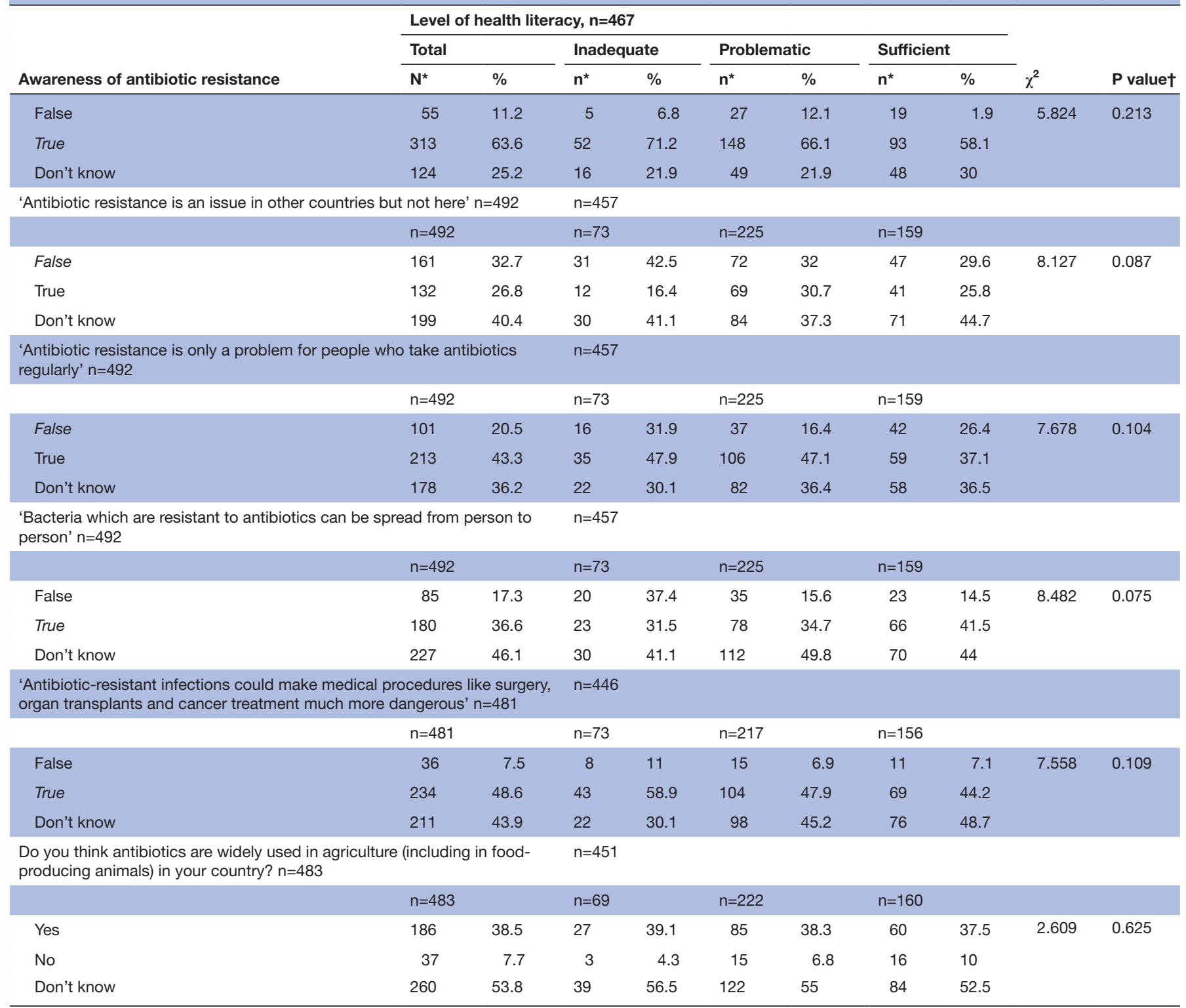

Correct answers are italicised.

Students' responses to questions about antibiotic resistance are presented in figures 1 and 2 .

Statistically significant $\mathrm{P}$-values $\leq 0.05$ are in bold.

*Some values are missing, missing data not included.

$+\chi^{2}$ test.

likely to have heard of the term 'antibiotic resistance' compared with those with lower educational levels, ${ }^{5}$ consistent with the current study results.

Only $11.2 \%$ of students in this study correctly responded to the question on whether the following statement was true or false: 'antibiotic resistance occurs when your body becomes resistant to antibiotics and they no longer work as well' and identified it as a false statement. This is compared with $22 \%$ of university students in Italy $^{35}$ and $28.7 \%$ of survey respondents in Germany. ${ }^{9}$ This suggests a high level of misunderstanding concerning this particular aspect of antibiotic resistance.

Awareness of AMR among Egyptian medical students/ professionals was satisfactory in $39.3 \%,{ }^{36} 48.3 \%{ }^{37}$ and
$60.5 \%{ }^{38}$ of respondents, while it was $47.4 \%$ among nonmedical students in the current study. However, there were still some misconceptions and malpractices reported among medical students/professionals. ${ }^{36-38}$ Regarding self-medication with antibiotics, $62.2 \%,{ }^{36} 65.9 \%^{39}$ and $77.7 \%^{37}$ of medical students reported such practice. These rates are higher than that observed among nonmedical students in the current study (39.9\%). Such findings require a more in-depth systematic investigation into the reasons behind the discrepancies in knowledge and practice among medical students/professionals.

The current study finding that sufficient HL and good antibiotic knowledge were significantly associated with students' high level of awareness of AMR should be 
mStrongly disagree = Disagree Neutral $\|$ Agree $\mid$ Strongly agree

People should use antibiotics only when they are prescribed by a doctor or nurse

Farmers should give fewer antibiotics to food-producing animals

People should not keep antibiotics and use them later for other illnesses

Parents should make sure all of their children's vaccinations are up-to-date

People should wash their hands regularly

Doctors should only prescribe antibiotics when they are needed

Governments should reward the development of new antibiotics

Pharmaceutical companies should develop new antibiotics

Percentage \% $100 \quad 80$

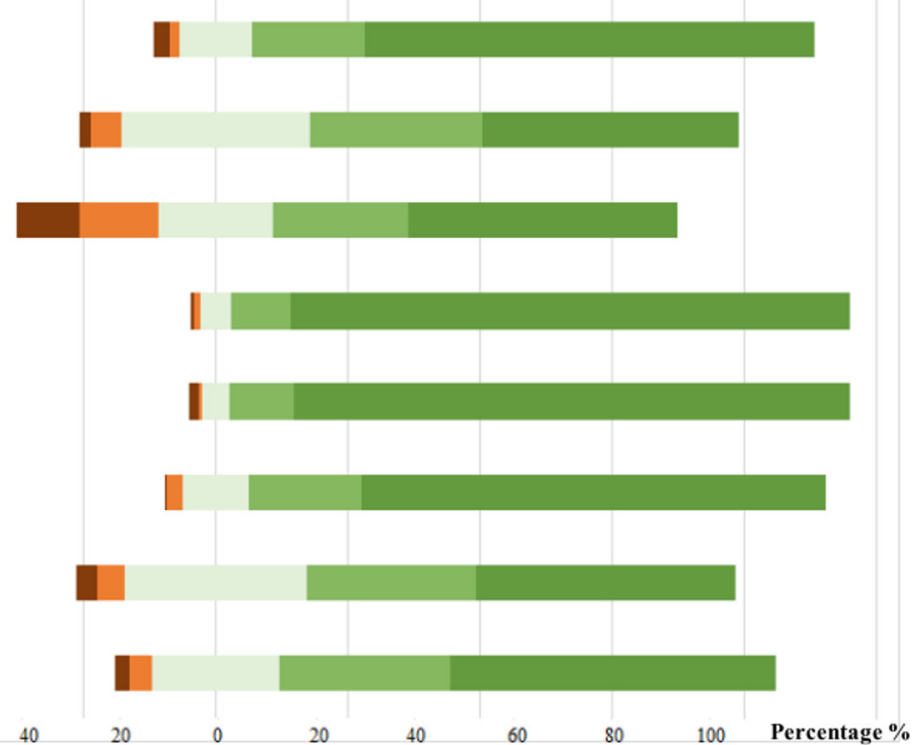

Figure 1 Percentage of students who strongly agree/agree/neutral/disagree/strongly disagree the actions would help address the problem of antibiotic resistance.

interpreted with caution, given the mixed conceptions about antibiotics among students with sufficient HL. The population-based study in Germany that examined the association between HL and knowledge of antibiotics reported supporting results. ${ }^{9}$ However, their survey was limited to only four questions, thus did not fully investigate antibiotic use, knowledge of antibiotics and awareness of AMR. More evidence is needed to examine the association between HL and correct knowledge and behaviour towards antibiotics use in HICs and LMICs. Improvements in HL, considering its several determinants, may achieve broader advancements in health, a progress that is greatly needed in Egypt and similar LMICs.

\section{Strengths and limitations}

The cross-sectional nature of the study cannot allow causal associations between students' HL and use of antibiotics, knowledge of antibiotics and awareness of AMR. Convenience sampling may have introduced selection bias, thus may not accurately represent the wider views of private and public university students in Egypt. However, the target sample size has been achieved and non-response and missing values have been taken into account, thus the minimal missing data and possible differences between responders and non-responders have unlikely biased the current study findings. The self-administered method

- Strongly disigree $\|$ Disigree $=$ Neutral $\|$ Agree $\|$ Strongly agree

I am not at risk of getting an antibiotic -resident infection, as long as I take my antibiotics correctly

I am worried about the impact that antibiotic resistance will have on my health, and that of my family

There is not much people like me can do to stop antibiotics resistance

Everyone needs to take responsibility for using antibiotics responsibly

Medical experts will solve the problem of antibiotic resistance before it becomes too serious

Antibiotics resistance is one of the biggest problems the world faces

Figure 2 Percentage of students who strongly agree/agree/neutral/disagree/strongly disagree with the statements. 
Table 6 Mean total percentage scores and awareness of antibiotic resistance among non-medical students by background characteristics and levels of health literacy

\begin{tabular}{|c|c|c|c|c|c|}
\hline \multirow[b]{3}{*}{ Characteristics } & \multirow[b]{3}{*}{$\mathbf{N}^{*}$} & \multirow[t]{2}{*}{$\begin{array}{l}\text { Mean total } \\
\text { percentage } \\
\text { score of } \\
\text { awareness } \\
\text { of antibiotics } \\
\text { resistance } \\
\end{array}$} & \multicolumn{3}{|c|}{ Level of awareness of antibiotics resistance } \\
\hline & & & Poor & Average & High \\
\hline & & Mean (SD) & $\mathrm{n}^{\star}(\%)$ & $\mathrm{n}^{\star}(\%)$ & $\mathrm{n}^{\star}(\%)$ \\
\hline Total & 463 & $56.2(13.6)$ & $115(24.8)$ & $312(67.4)$ & $36(7.8)$ \\
\hline Age (years) & & & $\mathrm{n}=115$ & $\mathrm{n}=312$ & $n=36$ \\
\hline $18-20$ & 230 & $54.2(13.5)$ & 68 (29.6) & 147 (63.9) & $15(6.5)$ \\
\hline$\geq 21$ & 233 & $58.2(13.4)$ & $47(20.2)$ & 165 (70.8) & $21(9.0)$ \\
\hline Statistic $†$ & & $F=0.000$ & $\chi^{2}=5.854$ & & \\
\hline$P$ value & & 0.001 & 0.021 & & \\
\hline Gender & $n=460$ & & $n=114$ & $\mathrm{n}=310$ & $n=36$ \\
\hline Males & 149 & 54.4 (12.9) & $39(26.2)$ & $104(69.8)$ & $6(4.0)$ \\
\hline Females & 311 & $57.2(13.9)$ & 75 (24.1) & $206(66.2)$ & $30(9.6)$ \\
\hline Statistic† & & $\mathrm{F}=1.819$ & $\chi^{2}=4.427$ & & \\
\hline$P$ value & & 0.037 & 0.11 & & \\
\hline Residence & $\mathrm{n}=463$ & & $n=115$ & $\mathrm{n}=312$ & $n=36$ \\
\hline Urban & 60 & $54.1(14.2)$ & $22(36.7)$ & $35(58.3)$ & $3(5.0)$ \\
\hline Suburban & 119 & $57.7(13.0)$ & $20(16.8)$ & 88 (73.9) & $11(9.2)$ \\
\hline Rural & 284 & $56.1(13.7)$ & $73(25.7)$ & $189(66.5)$ & $22(7.7)$ \\
\hline Statistic† & & $F=1.442$ & $\chi^{2}=9.001$ & & \\
\hline$P$ value & & 0.238 & 0.06 & & \\
\hline Marital status & $n=462$ & & $\mathrm{n}=115$ & $\mathrm{n}=311$ & $n=36$ \\
\hline Not married & 447 & $56.0(13.6)$ & $113(25.3)$ & $299(66.9)$ & $35(7.8)$ \\
\hline Married & 15 & $61.2(12.4)$ & $2(13.3)$ & $12(80.0)$ & $1(6.7)$ \\
\hline Statistic $†$ & & $\mathrm{~F}=0.111$ & $\chi^{2}=1.228$ & & \\
\hline$P$ value & & 0.739 & 0.653 & & \\
\hline Academic year & $n=463$ & & $\mathrm{n}=115$ & $n=312$ & $n=36$ \\
\hline 1 & 85 & 53.4 (12.9) & $28(32.9)$ & $51(60.0)$ & $6(7.1)$ \\
\hline 2 & 127 & $55.3(13.4)$ & $31(24.4)$ & 90 (70.9) & $6(4.7)$ \\
\hline 3 & 158 & $56.2(12.9)$ & $37(23.4)$ & $110(69.6)$ & $11(7.0)$ \\
\hline 4 & 86 & $60.4(14.7)$ & $17(19.8)$ & $57(66.3)$ & $12(14.0)$ \\
\hline 5 & 7 & $57.1(17.2)$ & 2 (28.6) & $4(57.1)$ & $1(14.3)$ \\
\hline Statistic $†$ & & $F=3.133$ & $\chi^{2}=10.787$ & & \\
\hline$P$ value & & 0.015 & 0.021 & & \\
\hline Health literacy & $n=431$ & & $\mathrm{n}=101$ & $\mathrm{n}=295$ & $n=35$ \\
\hline Inadequate & 71 & $54.4(15.7)$ & $24(33.8)$ & $44(62.0)$ & $3(4.2)$ \\
\hline Problematic & 208 & 56.7 (12.3) & $48(23.1)$ & $148(71.2)$ & $12(5.8)$ \\
\hline Sufficient & 152 & $57.9(13.7)$ & $29(19.1)$ & $103(67.8)$ & $20(13.2)$ \\
\hline Statistic† & & $F=1.728$ & $\chi^{2}=9.790$ & & \\
\hline$P$ value & & 0.179 & 0.002 & & \\
\hline
\end{tabular}

Statistically significant $P$-values $\leq 0.05$ are in bold.

*Some values are missing, missing data not included.

$\dagger \chi^{2}$ test or independent samples t-test or one-way analysis of variance. 
Table 7 Logistic regression analyses results of factors associated with good level of knowledge of antibiotics and high level of awareness of antibiotic resistance

\begin{tabular}{|c|c|c|c|c|c|c|c|c|}
\hline \multirow[b]{2}{*}{ Characteristic } & \multicolumn{4}{|c|}{$\begin{array}{l}\text { Good level of knowledge of antibiotics (vs poor } \\
\text { level of knowledge) }\end{array}$} & \multicolumn{4}{|c|}{$\begin{array}{l}\text { High level of awareness of antibiotic resistance (vs not } \\
\text { high level of awareness) }\end{array}$} \\
\hline & $\begin{array}{l}\text { Unadjusted OR } \\
(95 \% \mathrm{Cl})\end{array}$ & $\begin{array}{l}P \\
\text { value }\end{array}$ & $\begin{array}{l}\text { Adjusted OR } \\
(95 \% \mathrm{Cl})\end{array}$ & $\begin{array}{l}P \\
\text { value }\end{array}$ & $\begin{array}{l}\text { Unadjusted OR } \\
(95 \% \mathrm{Cl})\end{array}$ & $P$ value & $\begin{array}{l}\text { Adjusted OR } \\
(95 \% \mathrm{Cl})\end{array}$ & $P$ value \\
\hline \multicolumn{9}{|l|}{ Age (years) } \\
\hline $18-20$ & 1 & 0.057 & 1 & 0.219 & 1 & 0.319 & 1 & 0.507 \\
\hline$\geq 21$ & 1.5 (1.0 to 2.4 ) & & 0.6 (0.3 to 1.3$)$ & & 1.4 (0.7 to 2.8$)$ & & 0.7 (0.2 to 2.3 ) & \\
\hline Male & 1 & 0.061 & 1 & 0.064 & 1 & 0.042 & 1 & 0.095 \\
\hline Female & 1.6 (1.0 to 2.7 ) & & 1.6 (1.0 to 2.8 ) & & 2.5 (1.0 to 6.3 ) & & 2.2 (0.9 to 5.8 ) & \\
\hline \multicolumn{9}{|l|}{ Residence } \\
\hline Rural & 1 & & 1 & & 1 & & 1 & \\
\hline Suburban & 1.2 (0.6 to 2.6 ) & 0.645 & 1.1 (0.5 to 2.6$)$ & 0.8 & 1.9 (0.5 to 7.2$)$ & 0.326 & 1.7 (0.4 to 6.6$)$ & 0.483 \\
\hline Married & $2.0(0.7$ to 5.5$)$ & & $1.7(0.6$ to 5.1$)$ & & 0.8 (0.1 to 6.9$)$ & & 0.2 (0.0 to 2.0 ) & \\
\hline \multicolumn{9}{|l|}{ Academic year } \\
\hline 1 & 1 & & 1 & & 1 & & 1 & \\
\hline 2 & 1.7 (0.8 to 3.8 ) & 0.181 & 1.8 (0.8 to 4.1$)$ & 0.186 & 0.7 (0.2 to 2.1$)$ & 0.474 & 0.5 (0.2 to 1.7$)$ & 0.278 \\
\hline 3 & 2.8 (1.3 to 5.8 ) & 0.008 & 4.5 (1.7 to 11.8$)$ & 0.003 & 0.9 (0.4 to 2.8$)$ & 0.977 & 0.9 (0.2 to 4.1$)$ & 0.968 \\
\hline 4 & 3.0 (1.4 to 6.7 ) & 0.007 & 4.4 (1.4 to 13.5$)$ & 0.009 & 2.1 (0.8 to 5.9 ) & 0.149 & 2.6 (0.5 to 13.6$)$ & 0.245 \\
\hline 5 & 2.8 (0.5 to 5.8$)$ & 0.243 & 4.7 (0.7 to 31.4$)$ & 0.114 & 2.2 (0.2 to 21.3 ) & 0.498 & 3.4 (0.2 to 50.9$)$ & 0.371 \\
\hline \multicolumn{9}{|l|}{ Health literacy } \\
\hline Insufficient & 1 & & 1 & & 1 & & 1 & \\
\hline
\end{tabular}

Statistically significant $P$-values $\leq 0.05$ are in bold.

minimised interviewer bias and avoided social desirability in respondents' answers. Although self-reporting may have introduced recall bias in some answers, the surveyitems were adapted from previously tested questionnaires in different populations and in Egypt. Despite these limitations, considering this subpopulation's perceptions are important because the dynamic engagement of well-educated youth in this issue is vital to progress in containing AMR, specifically in a country where more than half of people report self-medication with antibiotics. Also, this study investigated in-depth several aspects in students' knowledge of antibiotic use that other studies on university students recommended addressing. ${ }^{26}$ Future studies using analytical designs such as longitudinal, or case-control studies could help provide robust evidence for causal associations.

\section{CONCLUSIONS}

HL was insufficient in this sample of non-medical Egyptian university students. A considerable proportion used antibiotics without prescription and believed antibiotics could treat self-limiting illnesses. Knowledge and awareness of antibiotic resistance were poor among these well-educated young adults and across all levels of HL, reflecting a profound deficiency in relevant education and communication programmes. However, findings suggest that sufficient HL is independently associated with students' high level of awareness of antibiotic resistance. Therefore, incorporating awareness raising curricula and public health education campaigns are an urgent necessity. In addition, public health awareness programmes on antibiotic use, coupled with national policies for controlling access and prescription of antibiotics are strongly recommended.

Acknowledgements The authors are grateful to the study respondents. Without their cooperation, this study would not have been possible. The authors are equally grateful to colleague medical students who assisted in data collection. The authors would like to thank Dr Isis Magdy for helping the students in the administrative paperwork to carry out this study. The authors would like to thank Dr Mostafa Yosef for providing guidance to the students during preliminary data analysis. 
Contributors AM conceptualised and designed the study, performed literature search, adapted the study tools, overseen pre-testing of the questionnaire, supervised study conduction, advised on data management, performed formal statistical data analysis, prepared the tables and figures, interpreted the data, wrote the final draft of the manuscript, and critically reviewed and edited it. The following authors have contributed equally in data collection and in searching the literature, in addition to their individual contributions: AA participated in conceptualisation of the study, participated in writing the first draft of results and in preliminary data analysis. SR participated in preliminary data analysis and writing the first draft of the introduction. SIA participated in writing the first draft of the methods and discussion. SKA participated in writing the first draft of the discussion. SA participated in writing the first draft of the introduction. SAM participated in writing the first draft of methods. TAZ participated in writing the first draft of the introduction and references.

Funding The authors have not declared a specific grant for this research from any funding agency in the public, commercial or not-for-profit sectors.

Competing interests None declared.

Patient consent for publication Not required.

Ethics approval The study was approved by the Research Ethics Committee, Faculty of Medicine, Ain Shams University, Cairo, Egypt (FMASUR122020). This study was evaluated to involve no or minimal risk to participants. University students had limited time to respond to the survey due to their busy study schedule, therefore, verbal consent was considered more practical in this low-risk survey.

Provenance and peer review Not commissioned; externally peer reviewed.

Data availability statement All data relevant to the study are included in the article or uploaded as supplemental information.

Supplemental material This content has been supplied by the author(s). It has not been vetted by BMJ Publishing Group Limited (BMJ) and may not have been peer-reviewed. Any opinions or recommendations discussed are solely those of the author(s) and are not endorsed by BMJ. BMJ disclaims all liability and responsibility arising from any reliance placed on the content. Where the content includes any translated material, BMJ does not warrant the accuracy and reliability of the translations (including but not limited to local regulations, clinical guidelines, terminology, drug names and drug dosages), and is not responsible for any error and/or omissions arising from translation and adaptation or otherwise.

Open access This is an open access article distributed in accordance with the Creative Commons Attribution Non Commercial (CC BY-NC 4.0) license, which permits others to distribute, remix, adapt, build upon this work non-commercially, and license their derivative works on different terms, provided the original work is properly cited, appropriate credit is given, any changes made indicated, and the use is non-commercial. See: http://creativecommons.org/licenses/by-nc/4.0/.

\section{ORCID iDs}

Aya Mostafa http://orcid.org/0000-0002-2803-2608

Abdurrahman Abdelzaher http://orcid.org/0000-0003-0721-4506

Salma Rashed http://orcid.org/0000-0002-5067-4412

Salma I AlKhawaga http://orcid.org/0000-0002-4993-2381

Shadwa K Afifi http://orcid.org/0000-0003-3481-3766

Shaimaa AbdelAlim http://orcid.org/0000-0001-6099-4287

Shaimaa A Mostafa http://orcid.org/0000-0003-1943-5453

Taha A Zidan http://orcid.org/0000-0001-5707-7285

\section{REFERENCES}

1 World Health Organization. Global action plan on antimicrobial resistance. Geneva, 2015. https://apps.who.int/iris/bitstream/handle/ 10665/193736/9789241509763_eng.pdf?sequence $=1$

2 World Health Organization. Regional office for Europe. Fact sheets on sustainable development goals: health targets. Antimicrobial resistance. Available: https://www.euro.who.int/en/health-topics/ health-policy/sustainable-development-goals/publications/2017/factsheets-on-the-sustainable-development-goals-sdgs-health-targets/ fact-sheet-on-the-sdgs-antimicrobial-resistance-2017

3 O'Neill J. Tackling drug-resistant infections globally: final report and recommendations. London: The Review on Antimicrobial Resistance, 2016. https://amr-review.org/sites/default/files/160518_Final\% 20paper_with\%20cover.pdf

4 World Bank Group. Drug-resistant infections. A threat to our economic future. final report. Washington, DC, 2017. http:// documents.worldbank.org/curated/en/323311493396993758/pdf/ final-report.pdf

5 World Health Organization. Antibiotic resistance multi-country public awareness survey. Geneva, 2015. https://apps.who.int/iris/bitstream/ handle/10665/194460/9789241509817_eng.pdf?sequence=1

6 Kasim K, Hassan H. Self-medication problem in Egypt: a review of current and future perspective. Int J Curr Res Rev 2018;10:40-5.

7 El-Nimr NA, Wahdan IMH, Wahdan AMH, et al. Self-medication with drugs and complementary and alternative medicines in Alexandria, Egypt: prevalence, patterns and determinants. East Mediterr Health $\mathrm{J}$ 2015;21:256-65.

8 El Ezz NFA, Ez-Elarab HS. Knowledge, attitude and practice of medical students towards self medication at Ain Shams University, Egypt. J Prev Med Hyg 2011;52:196-200.

9 Salm F, Ernsting C, Kuhlmey A, et al. Antibiotic use, knowledge and health literacy among the general population in Berlin, Germany and its surrounding rural areas. PLoS One 2018;13:e0193336.

10 Sørensen K, Van den Broucke S, Fullam J, et al. Health literacy and public health: a systematic review and integration of definitions and models. BMC Public Health 2012;12:80.

11 Awad Al, Aboud EA. Knowledge, attitude and practice towards antibiotic use among the public in Kuwait. PLoS One 2015;10:e0117910.

12 Wångdahl J, Lytsy P, Mårtensson L, et al. Poor health and refraining from seeking healthcare are associated with comprehensive health literacy among refugees: a Swedish cross-sectional study. Int J Public Health 2018;63:409-19.

13 Almaleh R, Helmy Y, Farhat E, et al. Assessment of health literacy among outpatient clinics attendees at Ain Shams university hospitals, Egypt: a cross-sectional study. Public Health 2017:151:137-45.

14 Ali NK, Ferguson RP, Mitha S, et al. Do medical trainees feel confident communicating with low health literacy patients? J Comm Hosp Intern Med Persp 2014;4:22893. doi:10.3402/jchimp.v4.22893

15 Zhang Y, Zhang F, Hu P, et al. Exploring health literacy in medical university students of Chongqing, China: a cross-sectional study. PLoS One 2016;11:e0152547.

16 Juvinyà-Canal $D$, Suñer-Soler $R$, Boixadós Porquet $A$, et al. Health literacy among health and social care university students. Int $J$ Environ Res Public Health 2020;17:2273.

17 Central Agency for Mobilization and Statistics. Egypt in numbers. education, 2019. Available: https://www.capmas.gov.eg/Pages/ StaticPages.aspx?page_id $=5035$

18 World Health Organization, Regional Office for Eastern Mediterranean. Initiating Egypt's antimicrobial resistance national action plan, 2017. Available: http://www.emro.who.int/egy/egyptevents/antimicrobial-resistance-national-action-plan.html

19 Ain Shams University. History. Available: http://www.asu.edu.eg/17/ page

20 Wångdahl J, Lytsy P, Mårtensson L, et al. Health literacy among refugees in Sweden - a cross-sectional study. BMC Public Health 2014;14:1030.

21 Sørensen K, Van den Broucke S, Pelikan JM, et al. Measuring health literacy in populations: illuminating the design and development process of the European health literacy survey questionnaire (HLSEU-Q). BMC Public Health 2013;13:948.

22 Röthlin F, Pelikan JM, Ganahl K. Die Gesundheitskompetenz Der 15-jährigen Jugendlichen in Österreich. Abschlussbericht Der österreichischen Gesundheitskompetenz Jugendstudie Im Auftrag des Hauptverbands Der österreichischen Sozialversicherungsträger (HVSV. Wien: Ludwig Boltzmann Institut Health Promotion Research. [Health Literacy of 15 year old adolescents in Austria. Final report of the Austrian Health Literacy youth study contracted by the Federation of Austrian Social Insurance Institutions (HVSV)], 2013. https://www.sozialversicherung.at/cdscontent/load?contentid= 10008.715507\&version $=1395738807$

23 Lorini C, Lastrucci V, Mantwill S, et al. Measuring health literacy in Italy: a validation study of the HLS-EU-Q16 and of the HLS-EU-Q6 in Italian language, conducted in Florence and its surroundings. Ann Ist Super Sanita 2019;55:10-18.

24 Sukys S, Cesnaitiene VJ, Ossowsky ZM. Is health education at university associated with students' health literacy? Evidence from cross-sectional study applying HLS-EU-Q. Biomed Res Int 2017;2017:8516843

25 World Health Organization. WHO guidelines for the regulatory assessment of medicinal products for use in self-medication. Geneva, 2000. http://apps.who.int/medicinedocs/pdf/s2218e/s2218e.pdf

26 Ruiz ME. Risks of self-medication practices. Curr Drug Saf 2010;5:315-23.

27 Kiyingi KS, Lauwo JA. Drugs in the home: danger and waste. World Health Forum 1993;14:381-4. 
28 Rather IA, Kim B-C, Bajpai VK, et al. Self-medication and antibiotic resistance: crisis, current challenges, and prevention. Saudi J Biol Sci 2017;24:808-12.

29 Jairoun A, Hassan N, Ali A, et al. University students' knowledge, attitudes, and practice regarding antibiotic use and associated factors: a cross-sectional study in the United Arab Emirates. Int $J$ Gen Med 2019;12:235-46.

30 Rathish D, Wijerathne B, Bandara S, et al. Pharmacology education and antibiotic self-medication among medical students: a crosssectional study. BMC Res Notes 2017;10:337.

31 Peng D, Wang X, Xu Y, et al. Antibiotic misuse among university students in developed and less developed regions of China: a crosssectional survey. Glob Health Action 2018;11:1496973.

32 Al-Azzam SI, Al-Husein BA, Alzoubi F, et al. Self-medication with antibiotics in Jordanian population. Int J Occup Med Environ Health 2007;20:373-80.

33 Laxminarayan R, Duse A, Wattal C, et al. Antibiotic resistance-the need for global solutions. Lancet Infect Dis 2013;13:1057-98.
34 Asogwa I, Offor S, Mbagwu H. Knowledge, attitude and practice towards antibiotics use among non-medical university students in Uyo, Nigeria. JAMPS 2017;15:1-11.

35 Prigitano A, Romanò L, Auxilia F, et al. Antibiotic resistance: Italian awareness survey 2016. J Infect Public Health 2018;11:30-4.

36 Assar A, Abdelraoof Ml, Abdel-Maboud M, et al. Knowledge, attitudes, and practices of Egypt's future physicians towards antimicrobial resistance (KAP-AMR study): a multicenter crosssectional study. Environ Sci Pollut Res Int 2020;27:21292-8.

37 Elden NMK, Nasser HA, Alli A. Risk factors of antibiotics selfmedication practices among university students in Cairo, Egypt. Open Access Maced J Med Sci 2020.

38 Tahoon MA, Khalil MM, Hammad E, et al. The effect of educational intervention on healthcare providers' knowledge, attitude, \& practice towards antimicrobial stewardship program at, National Liver Institute, Egypt. Egypt Liver Journal 2020;10:5.

39 Mohammed NA, Yousef YE. Antibiotic misuse among medical students in Sohag university. Egypt J Comm Med 2020;38:7-16. 